\title{
Antitumour necrosis factor- $\alpha$ agents and development of new-onset cirrhosis or non-alcoholic fatty liver disease: a retrospective cohort
}

\author{
Kuo-Tung Tang (D) , 1,2,3 Jean-François Dufour, ${ }^{4,5}$ Po-Hung Chen, ${ }^{6}$ \\ Ruben Hernaez, ${ }^{7,8}$ Susan Hutfless (i) ${ }^{6}$
}

To cite: Tang K-T, Dufour J-F, Chen $\mathrm{P}-\mathrm{H}$, et al. Antitumour necrosis factor- $\alpha$ agents and development of new-onset cirrhosis or non-alcoholic fatty liver disease: a retrospective cohort. BMJ Open Gastro 2020;7:e000349. doi:10.1136/ bmjgast-2019-000349

- Additional material is published online only. To view please visit the journal online (http://dx.doi.org/10.1136/ bmjgast-2019-000349).

Received 15 0ctober 2019 Revised 23 November 2019 Accepted 6 December 2019

\section{Check for updates}

(C) Author(s) (or their employer(s)) 2020. Re-use permitted under CC BY-NC. No commercial re-use. See rights and permissions. Published by BMJ.

For numbered affiliations see end of article.

Correspondence to Dr Susan Hutfless; shutfle1@jhmi.edu

\section{ABSTRACT}

Objective Elevated tumour necrosis factor (TNF)- $\alpha$ has been implicated in the progression of liver fibrosis and pathogenesis of non-alcoholic fatty liver disease (NAFLD). We aim to investigate the impact of anti-TNF- $\alpha$ agents on the development of cirrhosis and NAFLD.

Design This retrospective cohort study used a US claims database between 1 January 2010 and 31 December 2016. We identified adult patients with ankylosing spondylitis, inflammatory bowel disease, psoriatic arthritis or rheumatoid arthritis. Anti-TNF- $\alpha$ agents of interest included adalimumab, certolizumab, etanercept, golimumab and infliximab. The primary composite outcome was the development of new-onset cirrhosis, NAFLD or non-alcoholic steatohepatitis (NASH). The secondary outcomes were the development of (1) cirrhosis and (2) NAFLD or NASH. Propensity score for anti-TNF- $\alpha$ agent use was generated by logistic regression. Cox proportional hazard models adjusting for the propensity score were used with regard to time-varying anti-TNF- $\alpha$ agent exposure.

Results This study included 226555 incident patients with immune-related diseases. During the median 1.5 years follow-up, there was an increased hazard with antiTNF- $\alpha$ agent use in regard to liver outcomes (composite outcome HR: $1.47,95 \% \mathrm{Cl} 1.27$ to 1.70 ; cirrhosis HR $1.47,95 \% \mathrm{Cl} 0.96$ to 2.23 ; NAFLD or NASH HR 1.53 , $95 \% \mathrm{Cl} 1.32$ to 1.77). The composite outcome hazard was increased for each immune-related disease (HR 1.25-1.90).

Conclusion In the short term, we did not observe a beneficial effect of anti-TNF- $\alpha$ agent use for development of cirrhosis, NAFLD or NASH in patients with immunerelated diseases.

\section{INTRODUCTION}

The introduction of antitumour necrosis factor (TNF)- $\alpha$ agents in the 20th century revolutionised the treatment paradigm for patients with immune-related diseases. ${ }^{1}$ Their efficacy in achieving disease remission is well established in patients with diseases such as axial spondyloarthritis, inflammatory bowel disease (IBD), psoriatic arthritis (PsA) and

\section{Summary box}

What is already known about this subject:

- Animal models and human studies implicate the key role of tumour necrosis factor (TNF)- $\alpha$ in the progression of liver fibrosis and pathogenesis of nonalcoholic fatty liver disease.

What are the new findings

- This study demonstrates real-world data which did not show a beneficial effect regarding antiTNF- $\alpha$ agent use for development of cirrhosis or non-alcoholic fatty liver disease in patients with immune-related diseases.

How might it impact on clinical practice in the foreseeable future

- This study provides clues with respect to the potential hepatic effect of anti-TNF- $\alpha$ agent use in patients with immune-related diseases.

rheumatoid arthritis (RA), who fail to respond to conventional therapy. ${ }^{2-5}$ Real-world data provide an opportunity to examine various effects of this new class of drugs, in addition to approved indications. ${ }^{6}$ For example, some observational studies implied additional benefits including improved insulin resistance $^{7}$ and reduction of cardiovascular risk in anti-TNF- $\alpha$ agent users. ${ }^{8}$

Cirrhosis accounts for 1.16 million deaths per year worldwide, ranking the 11th most common cause of death. ${ }^{9}$ It originates from hepatic insult, resultant inflammation and then an untoward propagation of fibrosis. Hepatic inflammation is also implicated in the development and progression of non-alcoholic fatty liver disease (NAFLD), ${ }^{10} 11$ which is an increasingly recognised cause of cirrhosis worldwide. $^{12}$ TNF- $\alpha$, a crucial proinflammatory cytokine, has been recognised as one of the earliest participants in a variety of hepatic injuries. ${ }^{13}$ TNF- $\alpha$ antagonism alleviates hepatic 
inflammation and even reverses steatosis in rodent models of chronic liver diseases, including NAFLD. ${ }^{14-18}$ Interventional trials also alluded to the potential of anti-TNF- $\alpha$ agent in the suppression of hepatic inflammation/steatosis in humans. Pentoxiphylline, which inhibits TNF- $\alpha$, improved histological activity in 55 patients with non-alcoholic steatohepatitis (NASH) ${ }^{19}$ In addition, anti-TNF- $\alpha$ agent use led to clinical or histological improvement in hepatic inflammation among patients with alcoholic hepatitis or viral hepatitis. ${ }^{20-22}$ On the contrary, some animal studies implied a protective role of TNF- $\alpha$ in the liver ${ }^{23}$ and its antagonism may abolish this effect. ${ }^{24}$

Patients with immune-related diseases are at risk for liver damage, including hepatotoxicity of medications, exacerbation of underlying chronic viral hepatitis and concomitant autoimmune liver disease. ${ }^{25}$ NAFLD is also a common finding in these patients, with a prevalence around $20 \%{ }^{26}$ Thus, the combination of promoters of liver damage in the setting of NAFLD might lead to progression from simple steatosis to cirrhosis. We hypothesised that anti-TNF- $\alpha$ agent could reduce the risk for development of cirrhosis, NAFLD or NASH among patients with immune-related diseases. We, therefore, conducted a retrospective cohort study based on a claims database in the USA.

\section{METHODS}

\section{Study population}

This study analysed data obtained from the MarketScan Commercial Claims Database. We first identified adult $(\geqq$ 18) patients with International Classification of Diseases (ICD)-9 CM or ICD-10-CM diagnosis codes listed on at least two claims on different dates for ankylosing spondylitis (AS), IBD (Crohn's disease and/or ulcerative colitis),
PsA or RA from 1 January 2010 to 31 December 2016 (figure 1). Patients with one of these immune-related diseases enrolled in the database $\geqq 12$ months before the index date (the date of first diagnosis for the immunerelated disease) were eligible. Exclusion criteria included any claim for systemic lupus erythematosus, systemic sclerosis, autoimmune myositis or systemic vasculitis during enrolment in the database, to generate a more homogeneous study population. We also excluded prevalent cases of cirrhosis, NAFLD, NASH or chronic hepatitis $\mathrm{B} / \mathrm{C}$ on or prior to the index date, or anti-TNF- $\alpha$ agent use prior to the index date.

\section{Medications of interest}

Anti-TNF- $\alpha$ agents included adalimumab, certolizumab, etanercept, golimumab and infliximab. The identification of anti-TNF- $\alpha$ agent was based on both medication prescription claims using the National Drug Code numbers and administration claims based on Current Procedural Terminology codes (online supplementary table S1). The beginning of anti-TNF- $\alpha$ agent coverage was defined as the date of first anti-TNF- $\alpha$ agent claim. The end of anti-TNF- $\alpha$ agent coverage was defined as the last date of anti-TNF- $\alpha$ agent use based on prescription claims (date of prescription plus supply days) or administration claims (date of procedure plus a recommended dosing interval) (online supplementary table S2). Gaps of 84 days or fewer between anti-TNF- $\alpha$ agent use were considered continuous use.

\section{Liver outcomes}

The primary outcome was the development of a composite of cirrhosis (ICD-9-CM code 571.5; ICD-10-CM code K74.6x), NAFLD (ICD-9-CM code 571.8; ICD-10-CM

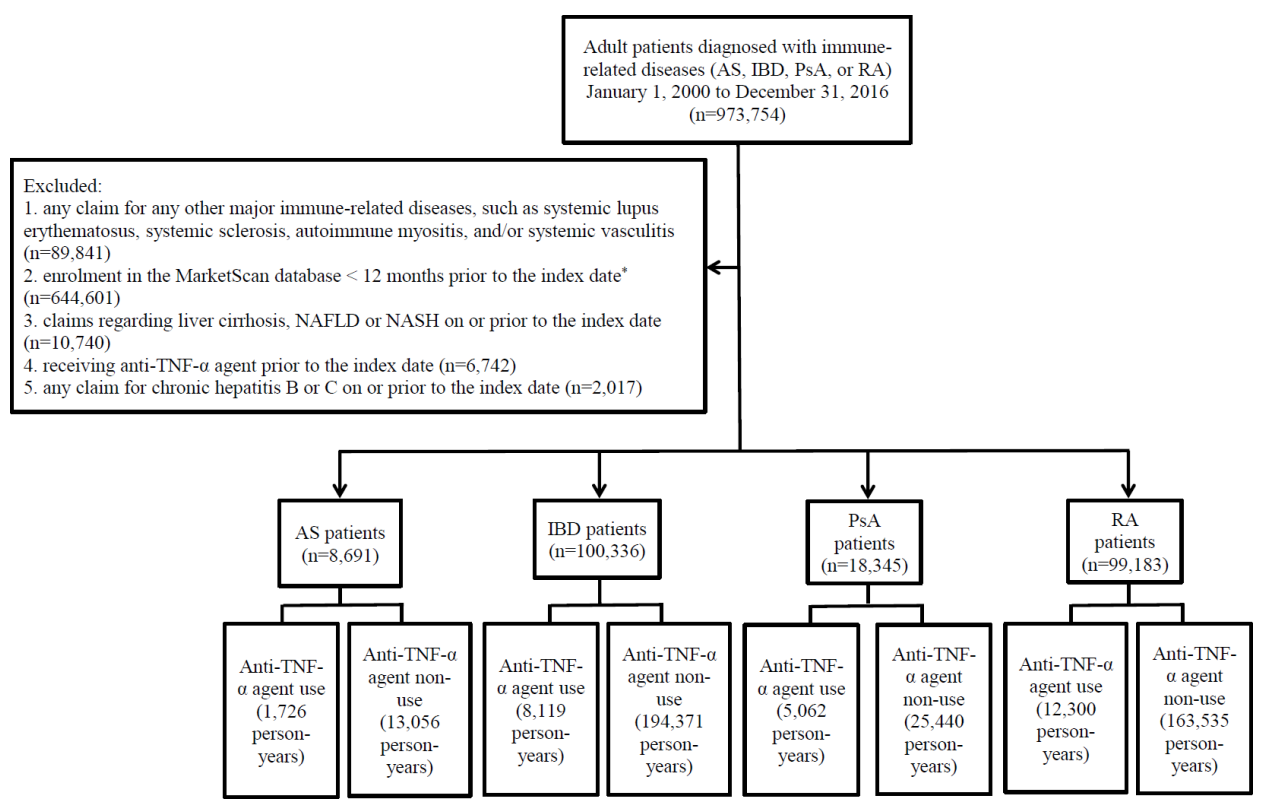

Figure 1 The study algorithm for identifying patients with immune-related diseases. *The index date, the date of first diagnoses for each immune-related disease. AS, ankylosing spondylitis; IBD, inflammatory bowel disease; NAFLD, nonalcoholic fatty liver disease; NASH, non-alcoholic steatohepatitis; PsA, psoriatic arthritis; RA, rheumatoid arthritis; TNF, tumour necrosis factor. 
codes K76.0) or NASH (no ICD-9-CM code available; ICD-10-CM code K75.81, after October 2015) with $\geqq$ two claims on different days. The two secondary outcomes were the development of either cirrhosis or NAFLD/ $\mathrm{NASH}$, for $\geqq$ two claims on different days. The first qualifying claim was considered the outcome date.

\section{Potential confounders}

Potential confounders included comorbidities and medications (online supplementary table S1). Diabetes mellitusrelated claims on or prior to the index date were collected. Steatogenic medications (corticosteroids and methotrexate) and other hepatotoxic medications (leflunomide, azathioprine and sulfasalazine) on or prior to the index date were captured. Patients having two prescription claims within 84 days since the index date were regarded as medication users. Use of other biologics, such as anti-interleukin (IL)-6 (tocilizumab), anti-IL-12/23 (ustekinumab), antiIL-17 (secukinumab, ixekinumab), abatacept or rituximab from the index date through the end of follow-up, was also identified based on both prescription and administration claims.

\section{Propensity score}

In order to control for observed confounders, a propensity score for anti-TNF- $\alpha$ agent use was calculated using logistic regression to adjust for difference in characteristics between anti-TNF- $\alpha$ agent users and non-users among patients with each immune-related disease (online supplementary table S3). A propensity score was created for each outcome because time-to-event analyses were used. Variables that are potentially associated with anti-TNF- $\alpha$ agent use or liver outcomes (age at index date, sex, diabetes mellitus, corticosteroids use, methotrexate use, other hepatotoxic medications use and other biologics use) were included in the propensity score models.

\section{Statistics}

Cohort characteristics were summarised as medians plus range and percentages. Anti-TNF- $\alpha$ agent non-users were followed from the index date until the occurrence of the outcome, or the end of enrolment in the database, whichever came first. Anti-TNF- $\alpha$ agent users were followed from the index date until the occurrence of the outcome, or the end of anti-TNF- $\alpha$ agent coverage, whichever came first. The incidence rate per 10000 person-years for outcomes in anti-TNF- $\alpha$ agent-exposed periods and non-exposed periods was calculated. The HRs for outcomes in antiTNF- $\alpha$ agent-exposed periods compared with non-exposed periods (treating anti-TNF- $\alpha$ agent exposure as a monotonic time-varying variable) were obtained using the Cox proportional hazards model for all patients and patients with each immune-related disease and included adjustment for propensity score. The proportional hazard assumption was checked by including time-by-covariate interactions in the model. ${ }^{27}$ If the proportional hazard assumption was violated, a piecewise Cox model was applied. ${ }^{28}$ In the piecewise Cox model, we assumed disparate constant proportional hazards before and after a certain timepoint. Such a violation occurred for IBD so we took the following steps: after examination of the survival curve constructed in the method of Simon and Makuch, ${ }^{29}$ we tested several cutoff time points and selected the one with the lowest Akaike information criterion. The need for informed consent was waived based on the deidentified nature of the claims database. Statistical analyses were conducted using SAS software V.9.4 (SAS Institute).

\section{Sensitivity analyses}

We performed several sensitivity analyses for primary composite outcome. First, we examined whether having one code only rather than two had a meaningful change in the inference. Second, we determined rates of clinical encounter, liver function test or liver sonography per year for each anti-TNF- $\alpha$ agent use and non-use period (within the first 84 days or the whole period) to detect potential surveillance bias (online supplementary table S4). We found that the difference was most prominent in regard to rate of clinical encounter within the whole period. We then adjusted for the rate of clinical encounter within the whole period as a time-varying covariate based on anti-TNF- $\alpha$ agent use and non-use period in the Cox model. Third, we examined if restricting patients to those who did not use methotrexate or corticosteroids changes the results. Finally, patients with other chronic liver diseases which are associated with cirrhosis (autoimmune hepatitis, primary biliary cirrhosis, primary sclerosing cholangitis, Wilson's disease, hemochromatosis, alpha-1-antitrypsin deficiency and alcoholic liver disease) were excluded before analyses. We also stratified our analyses by age, sex, methotrexate and hepatotoxic medications use.

\section{RESULTS \\ Baseline characteristics of identified patients}

RA patients were older, and had the highest proportion of females, diabetes mellitus, hypertension, dyslipidaemia and use of corticosteroids among all patients with immune-related diseases (table 1). Methotrexate, other hepatotoxic medications and other biologics were used most often in PsA patients. The median follow-up period was around 1.5 years for each immune-related disease.

\section{Characteristics of anti-TNF- $\alpha$ agent users and non-users}

The order of proportion of anti-TNF- $\alpha$ agent use by disease was as follows: PsA $>$ AS $>$ RA $>$ IBD. Anti-TNF- $\alpha$ agent non-users were older, and had a higher proportion of diabetes mellitus, hypertension, dyslipidaemia and a lower proportion of use of corticosteroids, methotrexate and other hepatotoxic medications, than anti-TNF- $\alpha$ agent users among patients with immune-related disease (table 2). The median time period of anti-TNF- $\alpha$ agent use was around 8 months ( 0.7 years) for each immunerelated disease. 


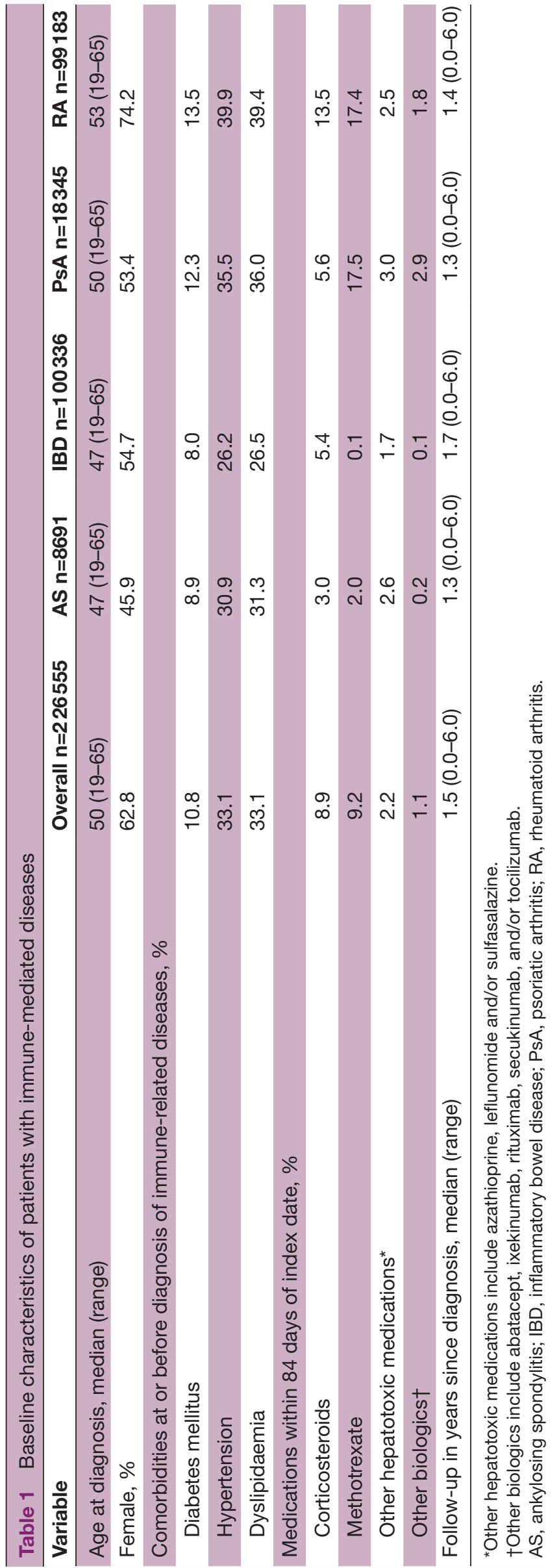

The impact of anti-TNF- $\alpha$ agent use on the development of liver outcomes

Overall, anti-TNF- $\alpha$ agent use was associated with an increased risk for the composite liver outcome when compared with periods of non-use (HR 1.47, 95\% CI 1.27 to 1.70) (table 3). This hazard was similar across diseases with the exception of IBD which was further increased (HR in the piecewise Cox model greater than 4 years: $3.4195 \%$ CI 1.67 to 6.96 ). There was an increased risk for cirrhosis (HR 1.47, 95\% CI 0.96 to 2.23), and an increased risk for NAFLD or NASH (HR 1.53, 95\% CI 1.32 to 1.77 ) in patients with immune-mediated diseases.

\section{Sensitivity analyses}

Sensitivity analyses using one encounter to define liver outcomes produced attenuated results compared with our case definition requiring two encounters (table 4). Adjustment for rates of clinical encounter also attenuated our results. Exclusion of patients with other chronic liver diseases did not influence our results. The results did not qualitatively change after restricting to patients who did not use MTX or corticosteroids. There appeared to be a decreasing $\mathrm{HR}$ for the composite liver outcome as regards to anti-TNF- $\alpha$ agent use with increasing age; in males; and in users of hepatotoxic medications.

\section{DISCUSSION}

Anti-TNF- $\alpha$ agent became an inseparable part of the treatment strategy for immune-related diseases in recent decades. In view of the potential role of TNF- $\alpha$ in the hepatic inflammatory response based on animal studies, we anticipated that anti-TNF- $\alpha$ use would lead to a decreased risk for cirrhosis, NAFLD or NASH in humans. However, we did not replicate these findings in this claims-based retrospective cohort study.

Previous human studies indicated a potential beneficial role of anti-TNF- $\alpha$ agent in the treatment of hepatic inflammation in alcoholic hepatitis ${ }^{2122}$ and chronic hepatitis $\mathrm{C},{ }^{20}$ though limited in clinical efficacy. ${ }^{30}{ }^{31}$ Hepatic inflammation could both initiate and maintain fibrogenesis, culminating in cirrhosis. ${ }^{32}$ A previous study of 48 PsA patients receiving anti-TNF- $\alpha$ agent showed that the progression of hepatic steatosis was halted 12 months later if minimal disease activity was achieved, when compared with those who maintained active disease. ${ }^{33}$ Determination of liver stiffness in 43 PsA patients found lower values in those treated with ant-TNF- $\alpha$ agent, suggesting an antifibrotic effect. ${ }^{34}$ Therefore, anti-TNF- $\alpha$ agent use might in turn withhold the progression to cirrhosis in chronic liver disease. However, we demonstrated no benefit with regard to anti-TNF- $\sigma$ agent use in the development of cirrhosis. The reasons underlying our observations are uncertain, but several explanations can be proposed. Patients treated with anti-TNF- $\alpha$ agent were more closely monitored by physicians. This might lead to more frequent diagnoses for cirrhosis, although monitoring for hepatotoxicity is also recommended in other 


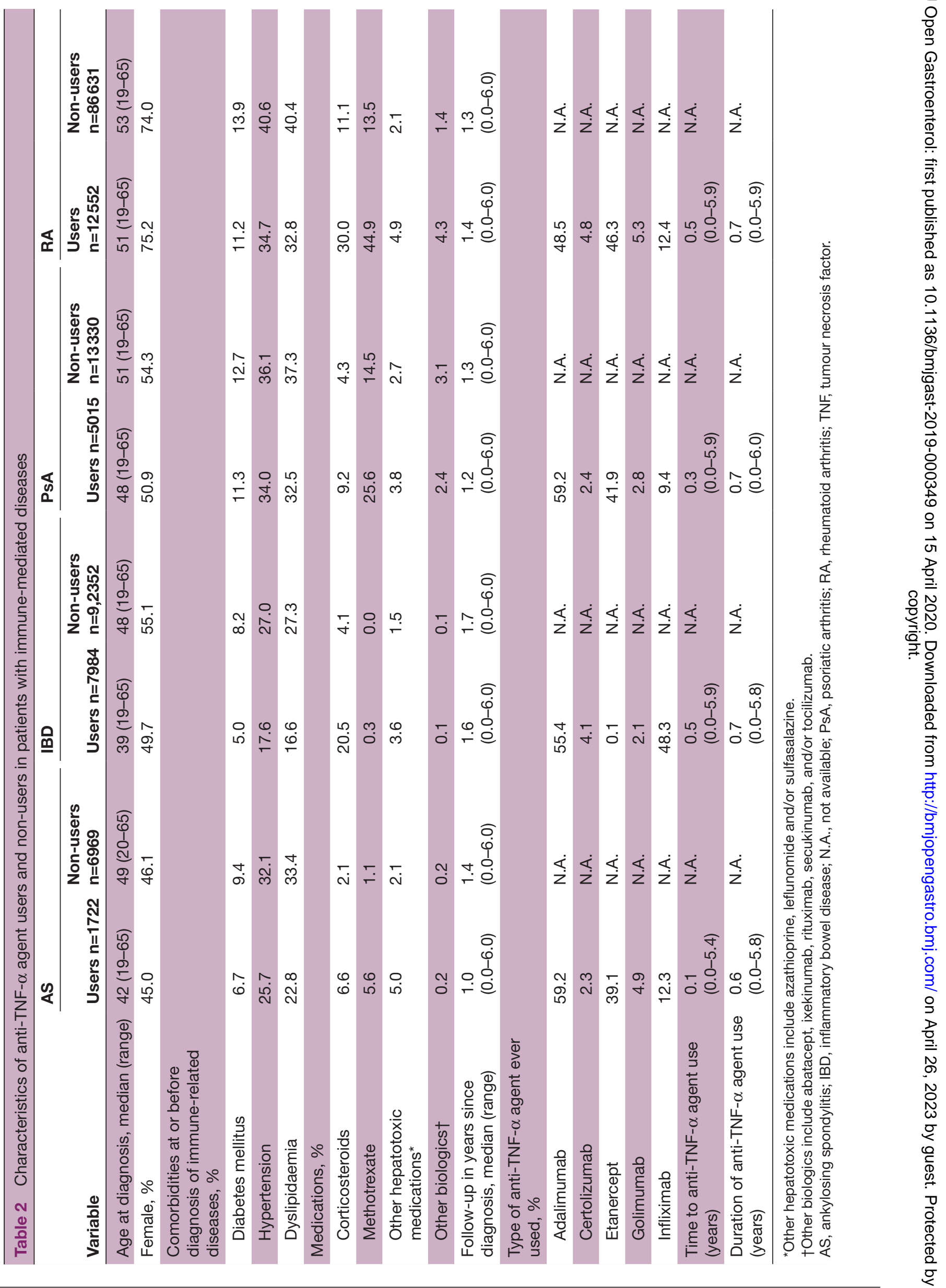


Table 3 Incidence rates and adjusted HRs for liver outcomes with respect to periods of anti-TNF- $\alpha$ agent use in patients with immune-related diseases

$\begin{array}{lllll}\text { Overall } & \text { AS } & \text { IBD } & \text { PsA } & \text { RA }\end{array}$

\begin{tabular}{|c|c|c|c|c|c|}
\hline \multicolumn{6}{|l|}{$\begin{array}{l}\text { Incidence rate } \\
\text { (per } 10000 \text { person-years) }\end{array}$} \\
\hline \multicolumn{6}{|c|}{ Composite outcome of cirrhosis, NAFLD or NASH } \\
\hline Anti-TNF- $\alpha$ agent use & 76.4 & 92.7 & 88.7 & 79.0 & 65.0 \\
\hline $\begin{array}{l}\text { Anti-TNF- } \alpha \text { agent non- } \\
\text { use }\end{array}$ & 64.7 & 52.8 & 67.8 & 72.7 & 60.7 \\
\hline \multicolumn{6}{|l|}{ Cirrhosis } \\
\hline $\begin{array}{l}\text { Anti-TNF- } \alpha \text { agent non- } \\
\text { use }\end{array}$ & 9.3 & 5.3 & 12.1 & 7.0 & 6.6 \\
\hline \multicolumn{6}{|l|}{ NAFLD or NASH } \\
\hline Anti-TNF- $\alpha$ agent use & 72.6 & 86.2 & 77.2 & 71.6 & 68.1 \\
\hline $\begin{array}{l}\text { Anti-TNF- } \alpha \text { agent non- } \\
\text { use }\end{array}$ & 57.4 & 50.9 & 57.9 & 66.5 & 56.0 \\
\hline \multicolumn{6}{|l|}{$\begin{array}{l}\text { Adjusted HR with } \\
\text { respect to anti-TNF- } \alpha \\
\text { agent use }(95 \% \mathrm{Cl})\end{array}$} \\
\hline Composite outcome & $\begin{array}{l}1.47 \\
(1.27 \text { to } 1.70)\end{array}$ & $\begin{array}{l}1.90 \\
(1.09 \text { to } 3.31)\end{array}$ & $\begin{array}{l}\leq 4 \text { years: }{ }^{*} \\
1.58 \\
(1.22 \text { to } 2.05) \\
>4 \text { years: } \\
3.41 \\
(1.67 \text { to } 6.96)\end{array}$ & $\begin{array}{l}1.25 \\
(0.88 \text { to } 1.76)\end{array}$ & $\begin{array}{l}1.30 \\
(1.03 \text { to } 1.65)\end{array}$ \\
\hline Cirrhosis & $\begin{array}{l}1.47 \\
(0.96 \text { to } 2.23)\end{array}$ & $\begin{array}{l}1.69 \\
(0.20 \text { to } 13.96)\end{array}$ & $\begin{array}{l}1.99 \\
(1.12 \text { to } 3.51)\end{array}$ & $\begin{array}{l}1.54 \\
\text { (0.51 to } 4.61)\end{array}$ & $\begin{array}{l}1.10 \\
\text { (0.48 to } 2.57)\end{array}$ \\
\hline NAFLD or NASH & $\begin{array}{l}1.53 \\
(1.32 \text { to } 1.77)\end{array}$ & $\begin{array}{l}1.81 \\
(1.02 \text { to } 3.21)\end{array}$ & $\begin{array}{l}\leq 4.5 \text { years:* } \\
1.59 \\
(1.21 \text { to } 2.08) \\
>4.5 \text { years:* } \\
3.90 \\
(1.60 \text { to } 9.48)\end{array}$ & $\begin{array}{l}1.21 \\
(0.84 \text { to } 1.74)\end{array}$ & $\begin{array}{l}1.47 \\
\text { (1.16 to } 1.85)\end{array}$ \\
\hline
\end{tabular}

*Results of a piecewise Cox model due to a significant time interaction with anti-TNF- $\alpha$ agent use. After examination of the survival curve constructed in Simon and Makuch's method, several cut-off time points were tested and the one with the lowest Akaike information criterion was selected.

AS, ankylosing spondylitis; IBD, inflammatory bowel disease; NAFLD, non-alcoholic fatty liver disease; NASH, non-alcoholic steatohepatitis; PsA, psoriatic arthritis; RA, rheumatoid arthritis; TNF, tumour necrosis factor.

hepatotoxic medication users ${ }^{35}$ and adjustment for clinical encounter rate in the sensitivity analysis did not qualitatively change the results. We excluded the possibility that the imbalance in methotrexate use was the reason for more cirrhosis by performing an analysis restricted to patients who did not take methotrexate. It can be argued that patients receiving anti-TNF- $\alpha$ agent were sicker and might drink more heavily. Finally the drugs themselves might be incriminated. Previous reports implied potential hepatotoxicity of anti-TNF- $\alpha$ agent, including idiosyncratic hepatic injury and autoimmune hepatitis. ${ }^{36}$

In the rat models, previous experiments implied a pivot role of TNF- $\alpha$ in the pathogenesis of NASH. ${ }^{11}$ Administration of infliximab could reverse diet-induced hepatic steatosis in rats. ${ }^{17} 18$ The sonographic stage of NAFLD also correlated with serum levels of TNF- $\alpha$ in individuals with morbid obesity. ${ }^{10}$ Pentoxyphylline is therapeutic for NASH perhaps through its inhibition of TNF- $\alpha{ }^{19}$ These findings imply the contributing role of TNF- $\alpha$ in the generation of hepatic steatosis. In the present study, however, we found an increased risk for development of NAFLD or NASH in patients with regard to anti-TNF- $\alpha$ agent use. Previous observations are conflicting in this regard. Likhitsup et al demonstrated a high prevalence (54\%) of NAFLD in 80 IBD patients under anti-TNF- $\alpha$ agent therapy. ${ }^{37} \mathrm{~A}$ meta-analysis of five studies in patients with IBD found mixed results, in which some studies even suggested an increased risk of NAFLD in anti-TNF- $\alpha$ agent users. ${ }^{38}$ Possible explanations for our findings include surveillance bias, as elaborated above. We excluded the possibility that the imbalance in methotrexate or corticosteroids use was the reason for more NAFLD or NASH by performing an analysis restricted to patients who did not take methotrexate or corticosteroids. There remains the possibility that patients requiring anti-TNF- $\alpha$ therapy are sicker and therefore less mobile and more prone to gain weight and develop NAFLD or NASH. Finally, several reports demonstrated that anti-TNF- $\alpha$ agent use are 


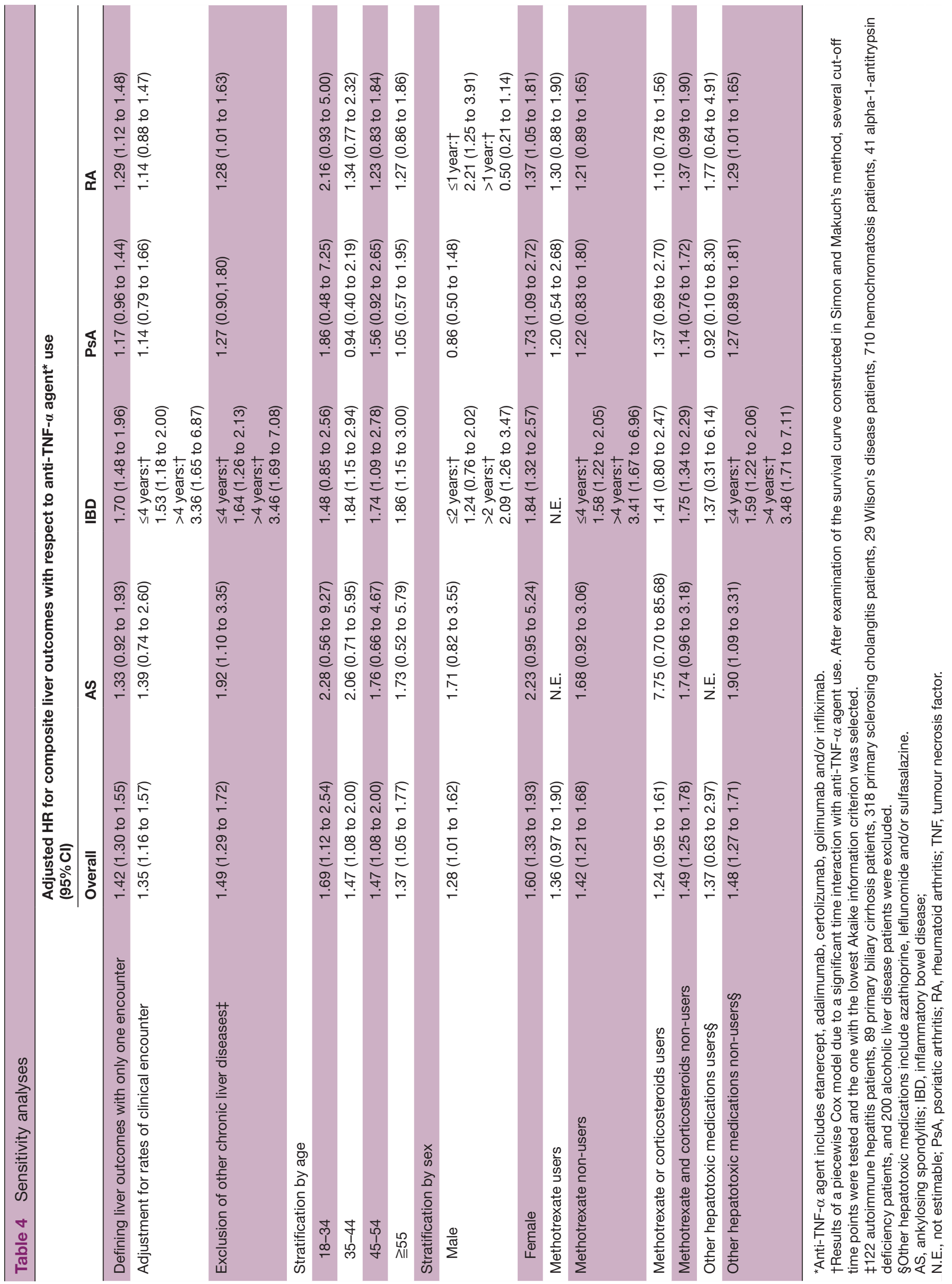


associated with weight gain ${ }^{39-42}$ and this may be related to an increased risk for NAFLD. ${ }^{43}$ Long-term studies are needed to identify these possible mechanisms.

Despite a well-documented pathogenic role, TNF- $\alpha$ is also found to plays a protective role in the liver. Animal studies have shown the cytoprotective function of TNF- $\alpha$, which is partially mediated by nuclear factor kappa light chain enhancer of activated B cells. ${ }^{23} 44$ A hepatic proliferative response is found in rats after systemic administration of TNF- $\alpha .{ }^{45}$ Antagonism by anti-TNF- $\alpha$ antibody suppresses rat liver regeneration after partial hepatectomy ${ }^{46}$ and aggravates hepatic steatosis in an acute liver injury rat model elicited by carbon tetrachloride. ${ }^{24}$ The crucial balance between beneficial and detrimental effects of TNF- $\alpha$ in hepatic microenvironment may also contribute to our findings.

There are several limitations of our study. Information regarding disease activity, overweight/obesity and smoking and alcohol status could not be reliably obtained in our database. ${ }^{47}$ The diagnoses of NAFLD, NASH or cirrhosis based on claims have inherent imprecision and may be underestimated, especially at baseline. ${ }^{48}$ Our anti-TNF- $\alpha$ agent non-users received a lower proportion of corticosteroids, methotrexate and other hepatotoxic medications, which possibly reflected a lower disease activity in anti-TNF- $\alpha$ agent non-users. This might partly explain our findings in terms of the development of cirrhosis, NAFLD or NASH, although a previous population-based study did not demonstrate an increased risk for cirrhosis in patients with AS, PsA and RA when compared with controls without immunerelated diseases. ${ }^{25}$ The relatively short period of median follow-up (1.5 years) and anti-TNF- $\alpha$ agent use (8 months) limited interpretation of our findings if there is a short-term increase in liver outcomes followed by a decrease in liver outcomes. Neither could we distinguish dose/duration differences with regard to anti-TNF- $\alpha$ agent use. However, we did not find a significant violation of proportional hazard assumption over time (up to around 6 years) in a substantial number of patients based on most of our models. For some models (patients with IBD) with assumption violations, we did not observe a decreased hazard over time in the piecewise analyses. To overcome limitations mentioned above, data from biological registries are expected to provide more sound evidence. ${ }^{6}$

In conclusion, in contrast to our hypothesis, we did not find a decreased hazard for development of cirrhosis, NAFLD or NASH with respect to anti-TNF- $\alpha$ agent use in patients with immune-related diseases.

\footnotetext{
Author affiliations

${ }^{1}$ Division of Allergy, Immunology and Rheumatology, Taichung Veterans General Hospital, Taichung, Taiwan

2Department of Epidemiology, Johns Hopkins University Bloomberg School of Public Health, Baltimore, Maryland, USA

${ }^{3}$ School of Medicine, National Yang-Ming University, Taipei, Taiwan

${ }^{4}$ Department of Visceral Surgery and Medicine, Inselspital University Hospital Bern, Bern, Switzerland
}

${ }^{5}$ Department of Biomedical Research, University of Bern, Bern, Switzerland ${ }^{6}$ Division of Gastroenterology \& Hepatology, Johns Hopkins University School of Medicine, Baltimore, Maryland, USA

${ }^{7}$ Section of Gastroenterology, Michael E DeBakey VA Medical Center, Houston, Texas, USA

${ }^{8}$ Center for Innovations in Quality, Effectiveness and Safety, Michael E DeBakey VA Medical Center, Houston, Texas, USA

Contributors $\mathrm{K}-\mathrm{TT}$ and $\mathrm{SH}$ designed and conceived the study, conducted data analysis, and drafted and revised the manuscript. J-FD, P-HC and RH revised the manuscript. All authors discussed the results and contributed to the final manuscript.

Funding K-TT received financial support from Taichung Veterans General Hospital and Veterans Affairs Council, R.O.C. P-HC is supported by National Center for Advancing Translational Sciences KL2TR001077. P-HC and SH are investigators at the Hopkins Digestive Diseases Basic \& Translational Research Core Center P30DK089502 and received support from the Helmsley Charitable Trust. RH is an investigator at the Center for Innovations in Quality, Effectiveness and Safety (CIN 13-413), Michael E. DeBakey VA Medical Center, Houston, Texas, USA.

Disclaimer The views expressed in this article are those of the authors and do not necessarily reflect the position or policy of the Department of Veterans Affairs or the United States government.

Competing interests None declared.

Patient consent for publication Not required.

Ethics approval This study was conducted in compliance with the Declaration of Helsinki and has been approved by the Institutional Review Board at Johns Hopkins University (IRB No. 00054790).

Provenance and peer review Not commissioned; externally peer reviewed.

Data availability statement Data are available on reasonable request.

Open access This is an open access article distributed in accordance with the Creative Commons Attribution Non Commercial (CC BY-NC 4.0) license, which permits others to distribute, remix, adapt, build upon this work non-commercially, and license their derivative works on different terms, provided the original work is properly cited, appropriate credit is given, any changes made indicated, and the use is non-commercial. See: http://creativecommons.org/licenses/by-nc/4.0/.

\section{ORCID iDs}

Kuo-Tung Tang http://orcid.org/0000-0002-5468-1329

Susan Hutfless http://orcid.org/0000-0002-6311-2611

\section{REFERENCES}

1 Kalden JR, Schulze-Koops H. Immunogenicity and loss of response to TNF inhibitors: implications for rheumatoid arthritis treatment. Nat Rev Rheumatol 2017;13:707-18.

2 Smolen JS, Landewé R, Bijlsma J, et al. EULAR recommendations for the management of rheumatoid arthritis with synthetic and biological disease-modifying antirheumatic drugs: 2016 update. Ann Rheum Dis 2017;76:960-77.

3 Gossec L, Smolen JS, Ramiro S, et al. European League against rheumatism (EULAR) recommendations for the management of psoriatic arthritis with pharmacological therapies: 2015 update. Ann Rheum Dis 2016;75:499-510.

4 Gionchetti P, Dignass A, Danese S, et al. 3Rd European evidencebased consensus on the diagnosis and management of Crohn's disease 2016: Part 2: surgical management and special situations. $J$ Crohns Colitis 2017;11:135-49.

5 Harbord M, Eliakim R, Bettenworth D, et al. Third European evidence-based consensus on diagnosis and management of ulcerative colitis. Part 2: current management. J Crohns Colitis 2017;11:769-84.

6 Zink A, Askling J, Dixon WG, et al. European biologicals registers: methodology, selected results and perspectives. Ann Rheum Dis 2009;68:1240-6.

7 Stagakis I, Bertsias G, Karvounaris S, et al. Anti-Tumor necrosis factor therapy improves insulin resistance, beta cell function and insulin signaling in active rheumatoid arthritis patients with high insulin resistance. Arthritis Res Ther 2012;14:R141.

8 Greenberg JD, Furer V, Farkouh ME. Cardiovascular safety of biologic therapies for the treatment of RA. Nat Rev Rheumatol 2011;8:13-21. 
9 Asrani SK, Devarbhavi H, Eaton J, et al. Burden of liver diseases in the world. J Hepatol 2019;70:151-71.

10 Paredes-Turrubiarte G, González-Chávez A, Pérez-Tamayo R, et al. Severity of non-alcoholic fatty liver disease is associated with high systemic levels of tumor necrosis factor alpha and low serum interleukin 10 in morbidly obese patients. Clin Exp Med 2016;16:193-202.

11 Kakino S, Ohki T, Nakayama $\mathrm{H}$, et al. Pivotal role of TNF- $\alpha$ in the development and progression of nonalcoholic fatty liver disease in a murine model. Horm Metab Res 2018;50:80-7.

12 Pais R, Barritt AS, Calmus Y, et al. Nafld and liver transplantation: current burden and expected challenges. J Hepatol 2016;65:1245-57.

13 Tilg $\mathrm{H}$, Diehl AM. Cytokines in alcoholic and nonalcoholic steatohepatitis. N Engl J Med 2000;343:1467-76.

14 limuro Y, Gallucci RM, Luster MI, et al. Antibodies to tumor necrosis factor alfa attenuate hepatic necrosis and inflammation caused by chronic exposure to ethanol in the rat. Hepatology 1997;26:1530-7.

15 Yin $\mathrm{M}$, Wheeler MD, Kono $\mathrm{H}$, et al. Essential role of tumor necrosis factor alpha in alcohol-induced liver injury in mice. Gastroenterology 1999;117:942-52

16 Tomita K, Tamiya G, Ando S, et al. Tumour necrosis factor alpha signalling through activation of Kupffer cells plays an essential role in liver fibrosis of non-alcoholic steatohepatitis in mice. Gut 2006;55:415-24.

17 Koca SS, Bahcecioglu IH, Poyrazoglu OK, et al. The treatment with antibody of TNF-alpha reduces the inflammation, necrosis and fibrosis in the non-alcoholic steatohepatitis induced by methionineand choline-deficient diet. Inflammation 2008;31:91-8.

18 Barbuio R, Milanski M, Bertolo MB, et al. Infliximab reverses steatosis and improves insulin signal transduction in liver of rats fed a high-fat diet. J Endocrinol 2007;194:539-50.

19 Zein CO, Yerian LM, Gogate P, et al. Pentoxifylline improves nonalcoholic steatohepatitis: a randomized placebo-controlled trial. Hepatology 2011;54:1610-9.

20 Zein NN, Etanercept Study G. Etanercept as an adjuvant to interferon and ribavirin in treatment-naive patients with chronic hepatitis $C$ virus infection: a phase 2 randomized, double-blind, placebo-controlled study. J Hepatol 2005;42:315-22.

21 Tilg H, Jalan R, Kaser A, et al. Anti-Tumor necrosis factor-alpha monoclonal antibody therapy in severe alcoholic hepatitis. J Hepatol 2003;38:419-25.

22 Spahr L, Rubbia-Brandt L, Frossard J-L, et al. Combination of steroids with infliximab or placebo in severe alcoholic hepatitis: a randomized controlled pilot study. J Hepatol 2002;37:448-55.

23 Wullaert A, van Loo G, Heyninck K, et al. Hepatic tumor necrosis factor signaling and nuclear factor-kappaB: effects on liver homeostasis and beyond. Endocr Rev 2007;28:365-86.

24 Dong Y, Liu Y, Kou X, et al. The protective or damaging effect of tumor necrosis factor- $\alpha$ in acute liver injury is concentrationdependent. Cell Biosci 2016;6:8.

25 Tung C-H, Lai N-S, Lu M-C, et al. Liver cirrhosis in selected autoimmune diseases: a nationwide cohort study in Taiwan. Rheumatol Int 2016;36:199-205.

26 Abraham S, Begum S, Isenberg D. Hepatic manifestations of autoimmune rheumatic diseases. Ann Rheum Dis 2004;63:123-9.

27 Bellera CA, MacGrogan G, Debled M, et al. Variables with timevarying effects and the COX model: some statistical concepts illustrated with a prognostic factor study in breast cancer. BMC Med Res Methodol 2010;10:20.

28 Zhou M. Understanding the COX regression models with TimeChange covariates. Am Stat 2001;55:153-5.

29 Smith AR, Goodrich NP, Beil CA, et al. Graphical representation of survival curves in the presence of time-dependent categorical covariates with application to liver transplantation. Journal of Applied Statistics 2018:1-12.
30 Naveau S, Chollet-Martin S, Dharancy S, et al. A doubleblind randomized controlled trial of infliximab associated with prednisolone in acute alcoholic hepatitis. Hepatology 2004;39:1390-7.

31 Chen $\mathrm{Y}-\mathrm{M}$, Chen $\mathrm{H}-\mathrm{H}$, Chen $\mathrm{Y}-\mathrm{H}$, et al. A comparison of safety profiles of tumour necrosis factor $\alpha$ inhibitors and rituximab therapy in patients with rheumatoid arthritis and chronic hepatitis C. Ann Rheum Dis 2015;74:626-7.

32 Czaja AJ. Hepatic inflammation and progressive liver fibrosis in chronic liver disease. World J Gastroenterol 2014;20:2515-32.

33 Di Minno MND, lervolino S, Peluso R, et al. Hepatic steatosis and disease activity in subjects with psoriatic arthritis receiving tumor necrosis factor- $\alpha$ blockers. J Rheumatol 2012;39:1042-6.

34 Seitz M, Reichenbach S, Möller B, et al. Hepatoprotective effect of tumour necrosis factor alpha blockade in psoriatic arthritis: a crosssectional study. Ann Rheum Dis 2010;69:1148-50.

35 Saag KG, Teng GG, Patkar NM, et al. American College of rheumatology 2008 recommendations for the use of nonbiologic and biologic disease-modifying antirheumatic drugs in rheumatoid arthritis. Arthritis Rheum 2008;59:762-84.

36 Lopetuso LR, Mocci G, Marzo M, et al. Harmful Effects and Potential Benefits of Anti-Tumor Necrosis Factor (TNF)- $\alpha$ on the Liver. Int $J$ Mol Sci 2018;19. doi:10.3390/ijms19082199. [Epub ahead of print: 27 Jul 2018]

37 Likhitsup A, Dundulis J, Ansari S, et al. High prevalence of non-alcoholic fatty liver disease in patients with inflammatory bowel disease receiving anti-tumor necrosis factor therapy. Ann Gastroenterol 2019;32:463-8.

38 Lapumnuaypol K, Kanjanahattakij N, Pisarcik D, et al. Effects of inflammatory bowel disease treatment on the risk of nonalcoholic fatty liver disease: a meta-analysis. Eur J Gastroenterol Hepatol 2018;30:854-60

39 Franchimont D, Roland S, Gustot T, et al. Impact of infliximab on serum leptin levels in patients with Crohn's disease. J Clin Endocrinol Metab 2005:90:3510-6.

40 Gisondi P, Cotena C, Tessari G, et al. Anti-Tumour necrosis factoralpha therapy increases body weight in patients with chronic plaque psoriasis: a retrospective cohort study. J Eur Acad Dermatol Venereol 2008;22:341-4

41 Florin V, Cottencin AC, Delaporte E, et al. Body weight increment in patients treated with infliximab for plaque psoriasis. J Eur Acad Dermatol Venereol 2013;27:e186-90.

42 Lutf A, Hammoudeh M. Weight gain and hair loss during anti-TNF therapy. Int J Rheumatol 2012;2012:1-3.

43 Fabbrini E, Sullivan S, Klein S. Obesity and nonalcoholic fatty liver disease: biochemical, metabolic, and clinical implications. Hepatology 2010;51:679-89.

44 Luedde T, Schwabe RF. NF-кB in the liver--linking injury, fibrosis and hepatocellular carcinoma. Nat Rev Gastroenterol Hepato 2011;8:108-18.

45 Feingold KR, Soued M, Grunfeld C. Tumor necrosis factor stimulates DNA synthesis in the liver of intact rats. Biochem Biophys Res Commun 1988;153:576-82.

46 Akerman P, Cote P, Yang SQ, et al. Antibodies to tumor necrosis factor-alpha inhibit liver regeneration after partial hepatectomy. Am J Physiol 1992;263:G579-85.

47 Al Kazzi ES, Lau B, Li T, et al. Differences in the prevalence of obesity, smoking and alcohol in the United States nationwide inpatient sample and the behavioral risk factor surveillance system. PLoS One 2015;10:e0140165.

48 Chalasani N, Younossi Z, Lavine JE, et al. The diagnosis and management of nonalcoholic fatty liver disease: practice guidance from the American association for the study of liver diseases. Hepatology 2018:67:328-57. 